\title{
Cellular Mechanisms Underlying Cholinergic and Noradrenergic Modulation of Neuronal Firing Mode in the Cat and Guinea Pig Dorsal Lateral Geniculate Nucleus
}

\author{
David A. McCormick \\ Section of Neurobiology, Yale University School of Medicine, New Haven, Connecticut 06510
}

The functional properties, ionic basis, and possible convergence and interaction of postsynaptic actions mediated by muscarinic and $\alpha_{1}$-adrenergic receptors were examined in cat and guinea pig dorsal lateral geniculate (LGNd) neurons maintained in thalamic slices in vitro. The possible involvement of GTP-binding proteins was also examined. Extracellular recordings from cat LGNd revealed the presence of two subpopulations of neurons. The most prevalent generated rhythmic high-frequency $(300-500 \mathrm{~Hz})$ bursts of two to six action potentials each, with an interburst frequency of 1-3 Hz. Intracellular recordings revealed that this activity is typical of thalamocortical relay cells in the apparent absence of neuromodulatory input. Application of ACh or noradrenaline (NA) to rhythmically oscillating neurons in the cat LGNd resulted in cessation of this activity followed by the appearance of single spike firing. Intracellular recordings revealed that this change in firing mode was associated with a depolarization of the neuron out of the range of intrinsic rhythmic oscillation and into or near the single spike firing mode. The voltage characteristics of the current underlying the cholinergic and noradrenergic slow depolarization were investigated in guinea pig LGNd neurons. Application of the muscarinic agonist acetyl- $\beta$-methylcholine (MCh) to presumed relay neurons resulted in a hyperpolarization due to the activation of an outward $\mathrm{K}^{+}$current. This response was followed by a slow depolarization due to reduction of a relatively non-voltage-dependent potassium current distinct from $I_{M}$ and $I_{\text {AHP. }}$. Application of NA resulted in a slow depolarization that was also associated with reduction of this relatively Inear $\mathrm{K}^{+}$current. The $\mathbf{M C h}$ - and NA-induced slow depolarizations displayed the property of occlusion, indicating convergence of action. However, these responses were mediated by pharmacologically distinct receptors since the MCh-induced reduction in $K^{+}$current was blocked by scopolamine while that induced by NA was blocked by the $\alpha_{1}$-adrenoceptor antagonist prazosin. Intracellular diffusion of GTP- $\gamma$-S resulted in the inward current responses to NA and MCh being irreversible, suggesting the possible involvement of a G-protein. Prior exposure to pertussis toxin did

Received June 12, 1991; revised Aug. 14, 1991; accepted Aug. 26, 1991.

This work was supported by the National Institute for Neurological Disorders and Stroke, the Klingenstein Fund, the Sloan Foundation, and the Jacobs Javits Center for Neuroscience.

Correspondence should be addressed to David A. McCormick, Section of Neurobiology SHM C303, Yale University School of Medicine, 333 Cedar Street, New Haven, CT 06510

Copyright (c) 1992 Society for Neuroscience $0270-6474 / 92 / 120278-12 \$ 05.00 / 0$ not affect the inward current response to NA and $\mathrm{MCh}$, while the outward $K+$ current responses induced by application of MCh or the $\mathrm{GABA}_{\mathrm{B}}$ agonist baclofen were blocked. These results reveal that activation of muscarinic or $\alpha_{1}$-adrenergic postsynaptic receptors in the LGNd result in a shift in firing mode from rhythmic oscillation to tonic single spike activity through a decrease in a relatively linear $K^{+}$current mediated through a pertussis toxin-insensitive $G$-protein. These neuromodulatory actions may underlie, in part, the shift in firing mode between rhythmic oscillation and tonic single spike activity in vivo associated with various states of sleep, arousal, and attentiveness.

Thalamocortical relay neurons in the dorsal lateral geniculate nucleus (LGNd) display marked changes in pattern of action potential gencration and excitability over the sleep-wake cycle or vigilance continuum (Livingstone and Hubel, 1981; Steriade and Deschênes, 1984; Steriade and Llinás, 1988). During periods of synchronized sleep, inattentiveness, or drowsiness, these neurons generate rhythmic high-frequency bursts of action potentials (McCarley et al., 1983). The shift to waking and attentiveness is associated with an abolition of these rhythmic highfrequency bursts, the appearance of single spike activity, and a marked increase in responsiveness to retinal inputs (Coenen and Vendrik, 1972; Livingstone and Hubel, 1981; McCarley et al., 1983). Intracellularly, this change in firing pattern is associated with tonic depolarization of the membrane and a cessation of large-amplitude, rhythmic inhibitory postsynaptic potentials (Hirsch et al., 1983; Steriade and Llinás, 1988). Stimulation in localized regions of the brainstem can mimic these changes in neuronal excitability in thalamic relay neurons, suggesting that ascending brainstem systems may be largely responsible for controlling the state of thalamic neuronal activity (reviewed in Steriade and McCarley, 1990). Anatomical, electrophysiological, and pharmacological investigations into the nature of these ascending activating pathways have implicated the brainstem cholinergic, noradrenergic, and serotoninergic systems in the extraretinal control of thalamic activity (reviewed in Steriade and Llinás, 1988; McCurmick, 1989; Steriade and McCarley, 1990). We have previously reported that application of $\mathrm{ACh}$ to cat or guinea pig LGNd relay neurons results in three different responses: a rapid depolarization associated with an increase in apparent input conductance mediated by nicotinic receptors; a small hyperpolarization mediated by an increase in $\mathrm{K}^{+}$conductance resulting from the activation of muscarinic receptors; and a slow depolarization associated with a decrease in $\mathrm{a} \mathrm{K}^{+}$ conductance mediated by muscarinic receptors (McCormick and 
Prince, 1987). We have also shown that application of noradrenaline (NA) to LGNd relay neurons can result in a large slow depolarization through a decrease in a $\mathrm{K}^{+}$conductance (McCormick and Prince, 1988). Recently we have demonstrated that in the lack of synaptic inputs, cat LGNd neurons in vitro display prominent rhythmic burst firing with interburst frequencies of approximately $1-3 \mathrm{~Hz}$ (McCormick and Pape, $1990 \mathrm{a}$ ), a pattern of activity that in vivo is associated with dccp slow-wave sleep or anesthesia (Lamarre et al., 1971; Curró Dossi et al., 1991b). Depolarization of oscillating neurons by 10-20 $\mathrm{mV}$ abolished this activity and switched the neuron to the single spike mode of action potential generation (McCormick and Pape, 1990a) that is characteristic of the waking and attentive state (Hirsch et al., 1983; McCarley et al., 1983). Although we have previously demonstrated that cholinergic- and noradrenergicinduced slow depolarizations generally inhibit burst firing and promote single spike activity (McCormick and Prince, 1987, 1988), the possibility that ACh and NA may be able to cause a complete switch to the tonic firing mode of rhythmically burstgenerating neurons has not yet been tested.

Here, we demonstrate that activation of either muscarinic or $\alpha_{1}$-adrenergic receptors results in an abolition of rhythmic burst firing and the promotion of single spike activity through the decrcasc of a rclativcly lincar $\mathrm{K}^{+}$current. This response appears to be mediated by a non-pertussis toxin-sensitive $\mathrm{G}$-protein.

\section{Materials and Methods}

Methods for preparation of thalamic slices and recording from lateral geniculate relay neurons are similar to those published previously (McCormick and Prince, 1987; McCormick and Pape, 1990a). Male or femalc adult Hartlcy guinca pigs werc decply anesthetized with sodium pentobartibal ( $35 \mathrm{mg} / \mathrm{kg}$, i.p.) and killed by decapitation. Three adult cats were preanesthetized with ketamine $(25 \mathrm{mg} / \mathrm{kg}, \mathrm{i} . \mathrm{m}$.), very deeply anesthetized with sodium pentobarbital $(25-35 \mathrm{mg} / \mathrm{kg}$, i.v.), and killed by decapitation. In both cases, the region of brain containing the dorsal lateral geniculate nucleus was removed, placed in cold $\left(5^{\circ} \mathrm{C}\right)$ bathing solution, and sectioned as $400-\mu \mathrm{m}$-thick slices on a Vibratome (Lancer Corporation). Thalamic slices were placed in an interface-style recording chamber (Fine Science Tools) and allowed to recover for at least $2 \mathrm{hr}$ before recording commenced. The bathing medium contained (in $\mathrm{mm}$ ) $\mathrm{NaCl}, 126 ; \mathrm{KCl}, 2.5 ; \mathrm{MgSO}_{4}, 1.2 ; \mathrm{NaH}_{2} \mathrm{PO}_{4}, 1.25 ; \mathrm{CaCl}_{2}, 2 ; \mathrm{NaHCO}_{3}$, 26 ; and dextrose, 10; and was aerated with $95 \% \mathrm{O}_{2}, 5 \% \mathrm{CO}_{2}$ to a final $\mathrm{pH}$ of 7.4 .

Agonists were applied by the pressure-pulse technique in that a brief (10-20 mscc, 207-345 kPa: 30-50 psi) pulse of nitrogen was applied to a broken microelectrode (tip diameter, $2-5 \mu \mathrm{m}$ ) containing the agonist dissolved in bathing medium. The volume of the resulting application was between 5 and $15 \mathrm{pl}$ as estimated from the diameter of the ejected droplet. Application to the exposed surface of the slice of agents that are not quickly removed from the extracellular space (e.g., baclofen, noradrenaline) was usually sufficient to elicit robust responses. However, in the case of acetylcholine and acetyl- $\beta$-methylcholine (MCh), it was necessary to lower the drug-applying pipette into the slice to obtain robust responses. Typically, the entry point of the drug-applying electrode was within $50 \mu \mathrm{m}$ of the recording electrode. Pertussis toxin was obtained from List Biological Laboratories (Campbell, CA), dissolved in the artificial cerebrospinal fluid detailed above $(1 \mu \mathrm{g} / \mu \mathrm{l})$, and injected in a volume of $1-2 \mu$ l directly into the LGNd of anesthetized $(0.7 \mathrm{gm} /$ $\mathrm{kg}$ chloral hydrate, i.p.) guinea pigs over a period of $5 \mathrm{~min}$ at the following coordinates: $4 \mathrm{~mm}$ posterior to bregma, $4.5 \mathrm{~mm}$ lateral to midline, $5.5 \mathrm{~mm}$ ventral to dura. The opposite LGNd of the same animal received an equal injection of the vehicle only. All other drugs were obtained from Sigma.

Extracellular single-unit recordings were obtained with tungsten microelectrodes and high-pass filtered with a cutoff frequency of $200 \mathrm{~Hz}$. Intracellular recordings were obtained with microelectrodes formed from "thin wall" glass (World Precision Instruments) on a Sutter Instruments $\mathrm{P}$-80/PC micropipette puller, filled with $4 \mathrm{M} \mathrm{K}$-acetate, with a final resistance of 35-50 M $\Omega$. Only data from those neurons that had stable resting membrane potentials negative to $-55 \mathrm{mV}$ and that generated action potentials that overshot $0 \mathrm{mV}$ were accepted for analysis.

Single-electrode voltage clamp was performed with an Axoclamp-2A amplifier connected to an IBM AT-style computer opcrating pCLAMP software (Axon Instruments). Switching frequencies were generally 3$4 \mathrm{kHz}$, and gain was between 0.5 and $1.0 \mathrm{nA} / \mathrm{mV}$. During current clamp, bridge balance was continuously monitored and adjusted, while during voltage clamp, headstage output was continuously monitored to insure adequate settling time of the microelectrode. Current versus voltage ( $I-$ $V)$ plots were obtained by steadily hyperpolarizing the neurons from a holding potential of $-55 \mathrm{mV}$ to between -120 and $-140 \mathrm{mV}$ over a period of 5-10 sec and measuring the amount of current required to do so. From 3 to 10 individual current traces obtained during voltage clamp were averaged to reduce noise.

\section{Results}

Extracellular recordings from neurons in the A-lamina of cat LGNd revealed two distinct populations. The most prevalent neuronal type recorded was found throughout the A-lamina and exhibited spontaneous high-frequency $(300-500 \mathrm{~Hz})$ burst discharges of two to six action potentials each, with the bursts occurring in a highly rhythmic manner of $1-3 \mathrm{~Hz}$ (e.g., Fig. $1 A$ ). This type of oscillatory activity is characteristic of deafferented or hyperpolarized thalamocortical relay cells in vivo (Steriade et al., 1985; Curró Dossi et al., 1991b; Steriade et al., 1992), and we have previously demonstrated that it occurs in cat thalamocortical relay neurons maintained in vitro (McCormick and Prince, 1988; McCormick and Pape, 1990a). This rhythmic activity is an intrinsic property of thalamocortical relay neurons and results largely from the interaction of the low-threshold $\mathrm{Ca}^{2+}$ current $I_{t}$ and the hyperpolarization-activated cation current $I_{h}$ (McCormick and Pape, 1990a).

The second physiological type of neuron recorded was less prevalent than the first, but also found throughout and between the A-lamina. This type of neuron exhibited unusually shortduration action potentials [mean, $0.9 \pm 0.1$ ( \pm SD) msec total duration vs. $1.5 \pm 0.2 \mathrm{msec}$ for rhythmically bursting neurons], spontaneously and continually generated single spike activity at a rate of 10-15 Hz (e.g., Fig. 1C), and never generated highfrequency burst discharges. We propose that this subpopulation of neurons represents a portion of local GABAergic interneurons based upon the following observations: deafferented relay neurons that are isolated from the thalamic reticular nucleus (nRt) in vivo receive a continuous barrage of IPSPs at a rate of 10-15 $\mathrm{Hz}$, presumably resulting from the spontaneous firing of local GABAergic interneurons (Steriade et al., 1985); intracellular recordings from morphologically defined interneurons reveal that these cells have unusually short-duration action potentials and do not readily generate high-frequency burst discharges (McCormick and Pape, 1988); and finally, application of ACh had a marked inhibitory influence upon the thin spiking neurons recorded here, with no signs of fast or slow excitation $(n=8$; Fig. 1C). We have reported previously that application of ACh to morphologically identified interneurons in the cat LGNd results in marked inhibition through activation of a $\mathrm{K}^{+}$conductance (McCormick and Pape, 1988). Here, we concentrated on the modulatory actions of ACh and NA on the rhythmically bursting presumed relay neurons.

Local application of $\mathrm{ACh}$, or the muscarinic agonist $\mathrm{MCh}(5$ mм in micropipette), to rhythmic burst-generating neurons resulted in a cessation of rhythmic burst firing, followed by a brief period of silence and then by the appearance of single spike activity ( $n=10$; Fig. $1 A$ ). Recovery was associated with a silent period followed by the reappearance of rhythmic burst firing 

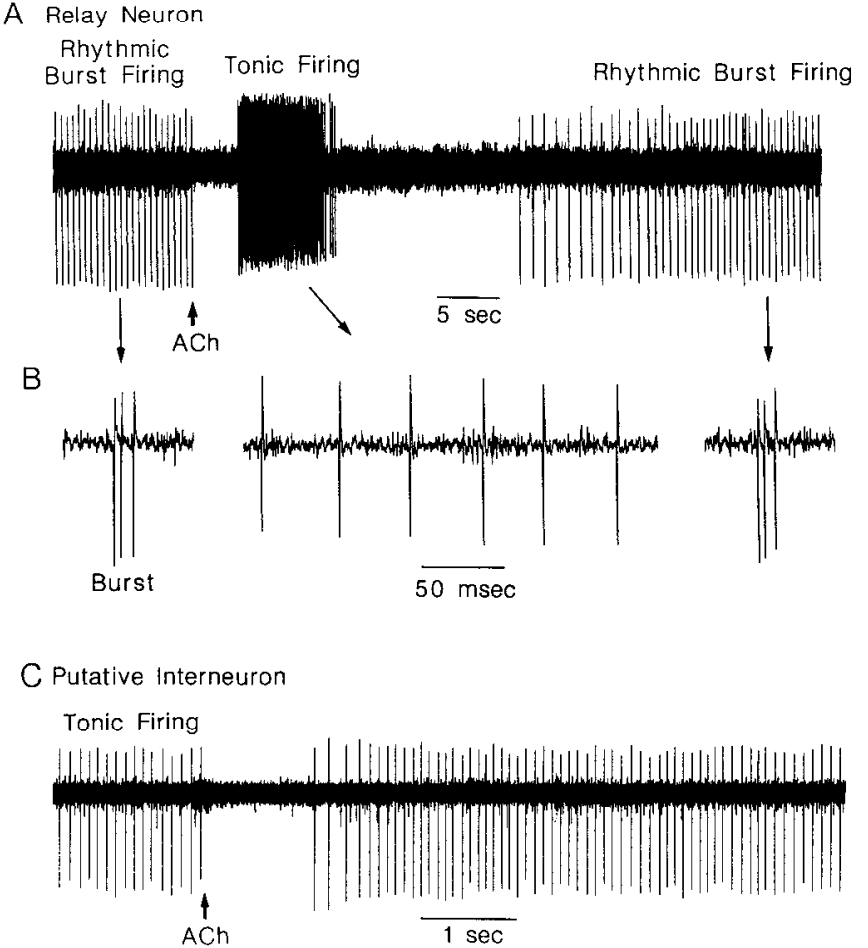

Figure 1. Application of ACh to a rhythmically bursting presumed relay neuron in the cat LGNd results in a cessation of burst activity and the appearance of tonic, or single spike, firing. After a delay, rhythmic burst firing reappears and returns to the baseline frequency of $2 \mathrm{HIz}$. Each vertical line prior to application of ACh represents a high-frequency burst of three to five action potentials. One such burst is expanded for illustration in $B$. $C$, Putative local interneurons were characterized by tonic firing at $10-15 \mathrm{~Hz}$. Application of $\mathrm{ACh}$ to these cells resulted in a brief $(1-5 \mathrm{sec})$ period of inhibition.

(Fig. 1A). Similarly, application of NA ( $500 \mu \mathrm{M}$ in micropipette) to rhythmically bursting cat LGNd neurons also resulted in an abolition of this activity and its replacement with single spike firing, for 1-2 min (not shown). Again, recovery was associated with a return to rhythmic, $1-3 \mathrm{~Hz}$ oscillation.

The cellular mechanisms through which ACh and NA exert these effects on LGNd neurons were examined through intracellular recordings. Intracellular recordings from presumed thalamocortical relay neurons in the cat LGNd revealed in a subpopulation of neurons a tendency to generate rhythmically lowthreshold $\mathrm{Ca}^{2+}$ spikes at a rate of $1-3 \mathrm{~Hz}$, as we have reported previously (McCormick and Pape, 1990a). The incidence with which rhythmic burst activity was recorded with intracellular micropipettes was lower than that suggested by extracellular recordings, perhaps due to disruption of the oscillation by the induction of a slight shunt caused by impalement of the neuron. Application of ACh or NA to rhythmically oscillating neurons resulted in a depolarization associated with the cessation of rhythmic burst firing (Fig. 2A,C). The depolarization to ACh possessed two distinct phases (Fig. $2 A$, arrows), which we have previously demonstrated to be due to the activation of nicotinic followed by muscarinic receptors (McCormick and Prince, 1987). Although we did not observe a complete switch of the neuron to the single spike firing mode with intracellular recordings in response to NA or $\mathrm{ACh}$, the agonist-induced depolarizations could be large enough to bring the membrane potential within a few millivolts of single spike firing threshold (Fig. 2A). The ability of ACh and NA to switch the firing mode of the neuron appears to result largely, if not entirely, from depolarization of the membrane, since similar depolarizations induced through the injection of current into the neuron had an identical effect (Fig. 2D).

Intracellular examination of responses to $\mathrm{NA}$ and $\mathrm{ACh}$ in guinea pig LGNd neurons have revealed slow depolarizing responses similar to those seen in cat LGNd relay cells (McCormick and Prince, 1987, 1988). Although we have found species differences in the prevalence of nicotinic responses and muscarinic receptor-mediated increases in potassium conductances between guinea pig and cat LGNd neurons, the similarity of the slow depolarizing responses suggests that the ionic basis for these may be the same. Therefore, we investigated the ionic basis of cholinergic and noradrenergic depolarization in guinea pig LGNd neurons using both current-clamp and single-electrode voltageclamp techniques.

The similarity of the ACh- and NA-induced slow depolarizations in guinea pig LGNd neurons suggests that they may be reducing the same $\mathrm{K}^{+}$conductance. To test this possibility, we examined the property of occlusion on NA and ACh responses in guinea pig LGNd neurons. In addition, single-electrode voltage-clamp techniques were also used to investigate further the voltage-dependent properties of the $\mathrm{K}^{+}$conductance reduced by $\mathrm{NA}$ and $\mathrm{ACh}$.

Stable intracellular recordings were obtained from 65 neurons in the guinea pig LGNd. A representative sample of 20 neurons possessed an average resting membrane potential of $-66 \pm 4$ $\mathrm{mV}$, input resistance of $42 \pm 14 \mathrm{M} \Omega$, and spike amplitude of $92 \pm 5 \mathrm{mV}$. The electrophysiological properties of these neurons were similar to those previously reported for thalamocortical relay cells (Jahnsen and Llinás, 1984a,b; McCormick and Pape, 1988), and therefore it is assumed that they are of this morphological class.

\section{Nonaddilivity of $N A$ - and ACh-induced slow depolarizations}

The possibility that activation of muscarinic and $\alpha_{1}$-adrenergic receptors may result in a decrease in the same $\mathrm{K}^{+}$conductance was examined by investigating the effect of maximal activation of adrenergic receptors on the response to muscarinic receptor stimulation and vice versa. Application of the muscarinic agonist MCh to guinea pig LGNd relay neurons resulted in not only a slow depolarizing response, but also initially a substantial hyperpolarizing response as well, as we have previously reported (Fig. 3A, Normal; McCormick and Prince, 1987). These two responses are mediated by an increase followed by a decrease in $\mathrm{K}^{+}$conductance (McCormick and Prince, 1987). Local application of a maximal dose (defined as a dose at which further applications did not increase the amplitude of the response) of NA resulted in a slow depolarization and action potential discharge (Fig. $3 A$, NA). The neuron was then hyperpolarized back to the pre-NA resting membrane potential with the injection of inward current ( - d.c.). A second application of MCh now resulted in the hyperpolarizing response only; no slow depolarization was evident (Fig. $3 A$, NA; $n=4$ ). This effect was revirsible (Fig. $3 A$, Recovery).

The possibility that maximal activation of muscarinic receptors may block the response to NA was examined through the use of the potent and long-lasting muscarinic agonist muscarine ( $5 \mathrm{mM}$ in micropipette). Local application of NA prior to muscarine resulted in a typical slow depolarization (Fig. $3 B$, Normal). Application of muscarine resulted in a prolonged hyper- 
A

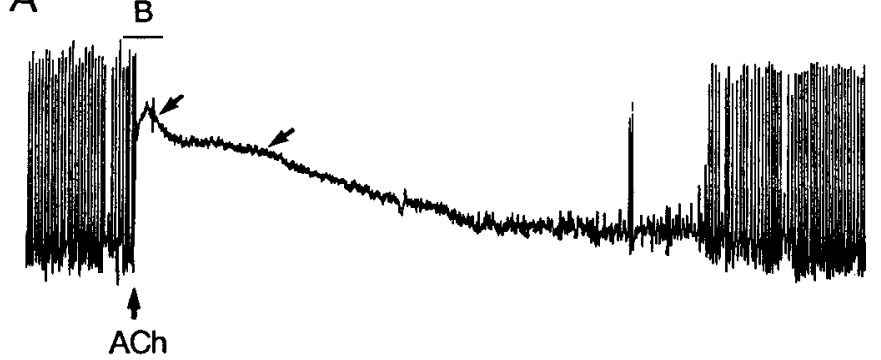

C

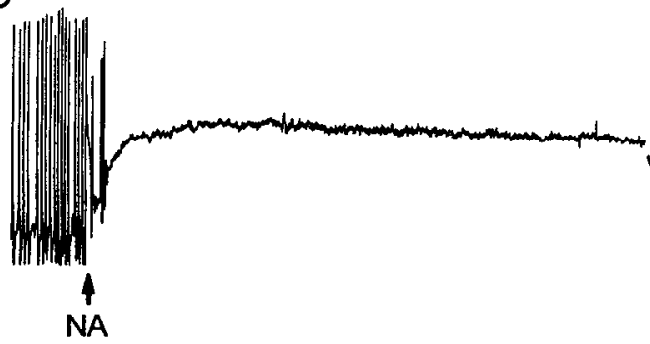

B
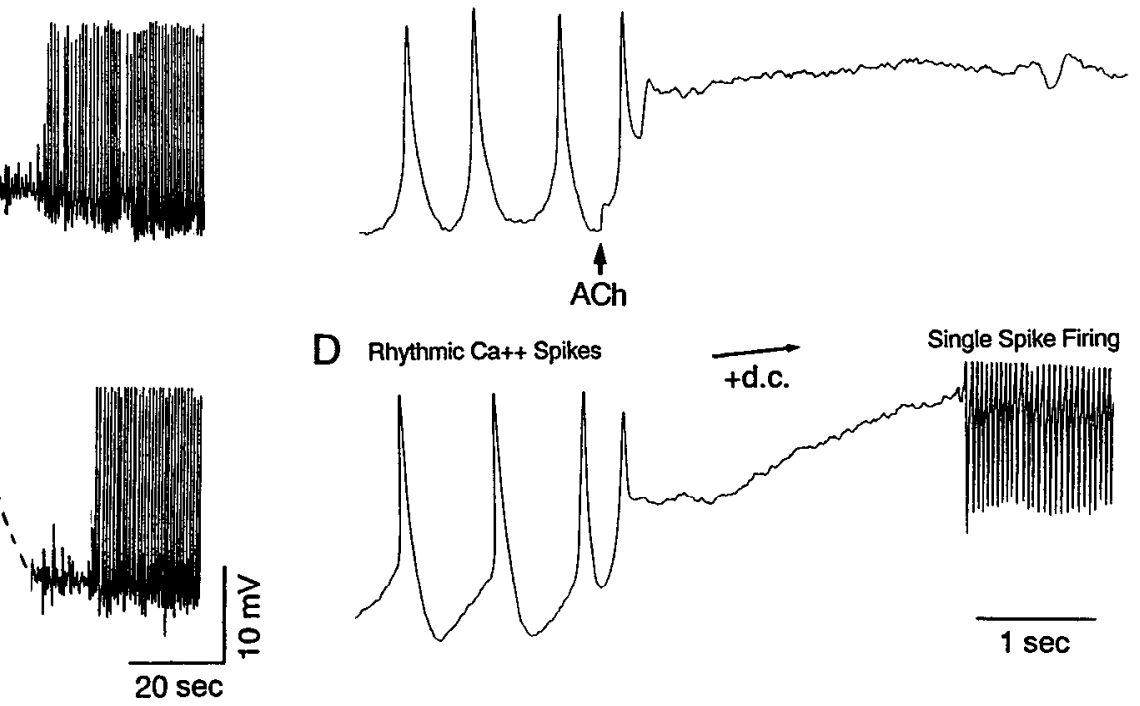

D Rhythmic Ca++ Spikes

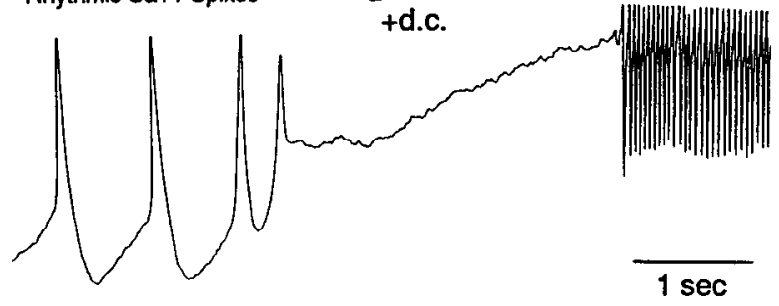

Figure 2. Abolition of the rhythmic gencration of $\mathrm{Ca}^{2+}$ spikes by $\mathrm{ACh}$ and NA in cat LGNd relay neurons. A, Intracellular recording of a cat LGNd neuron that spontaneously generated rhythmic $\mathrm{Ca}^{2+}$ spikes at resting membrane potential (each vertical line is one Ca ${ }^{2+}$ spike) at a rate of approximately $1.5 \mathrm{~Hz}$. In this particular cell, the $\mathrm{Ca}^{2+}$ spikes were just subthreshold for the generation of fast $\mathrm{Na}^{+} / \mathrm{K}^{+}$-mediated action potentials. Application of ACh resulted in a marked depolarization that decayed in two distinct phases (arrows). At the end of the response to ACh, rhythmic burst firing reappeared. $B$, Expanded portion of $A$ illustrates rhythmic low-threshold $\mathrm{Ca}^{2+}$ spikes and depolarization induced by $A C h$. $C$, Application of NA to this neuron also results in a marked slow depolarization and abolition of rhythmic $\mathrm{Ca}^{2+}$ spikes. $D$, Intracellular injection of depolarizing current $(+d . c$.) also resulted in an abolition of rhythmic burst firing and could switch the neuron to the single spike (tonic) mode of action potential generation. All data were obtained from the same cat LGNd neuron in lamina A1. Membrane potential at the most negative point during oscillation was $-80 \mathrm{mV}$.

polarization followed by a slow depolarization (Fig. $3 B$, Muscarine). Applications of NA during the muscarine-induced slow depolarization, and after compensation of the depolarization with the intracellular injection of current, revealed the NA response to be almost completely blocked (Fig. 3B, Muscarine).
These results suggest that NA- and MCh-induced slow depolarizations occur through reduction of the same $\mathrm{K}^{+}$current and/ or activation of the same second-messenger system in thalamocortical relay cells.

The pharmacological identity of the receptors mediating these
A

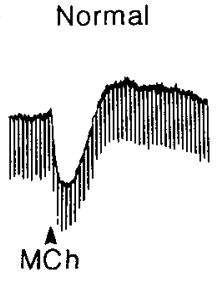

B

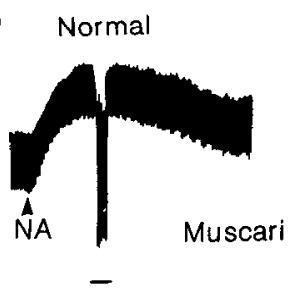

NA

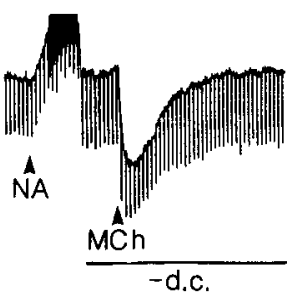

Muscarine

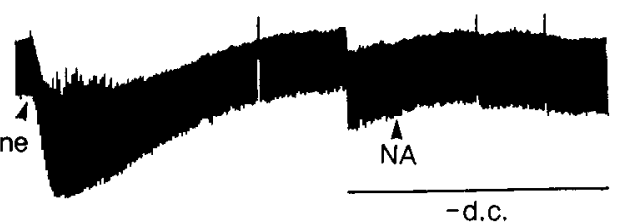

Recovery

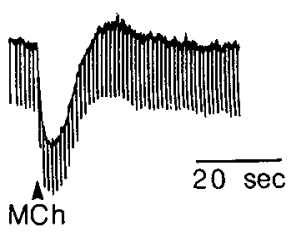

Recovery

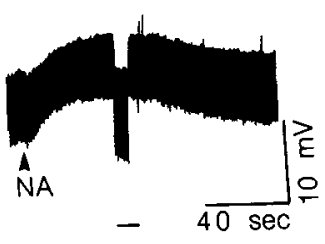

Figure 3. Nonadditivity of MCh- and NA-induced slow depolarizations in guinea pig IGNd neurons. A, Application of the muscarinic agonist MCh results in a typical hyperpolarization-slow depolarization sequence. Application of NA results in a slow depolarization. Intracellular injection of depolarizing current $(-d . c$. $)$ is then used to bring the membrane potential back to pre-NA baseline. A second application of MCh at this time results in the hyperpolarizing response only. This effect is reversible (Recovery). B, Application of N $\Lambda$ results in typical slow depolarization and decrease in membrane conductance (Normal; bar indicates adjustment of membrane potential with current injection). Application of the potent and long-lasting muscarinic agonist muscarine results in a prolonged hyperpolarization followed by a small slow depolarization. Again, intracellular injection of hyperpolarizing current $(-d . c$.) is used to compensate for the slow depolarization. A second application of NA now results in only a very small depolarizing response. This effect is partially reversible (Recovery). 
Normal

A
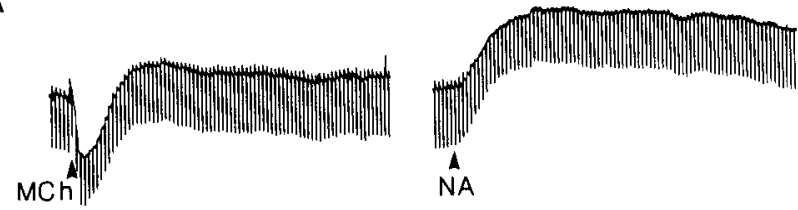

B

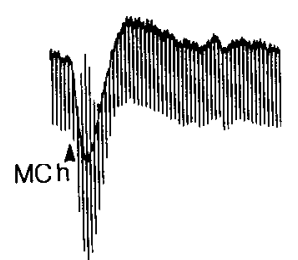

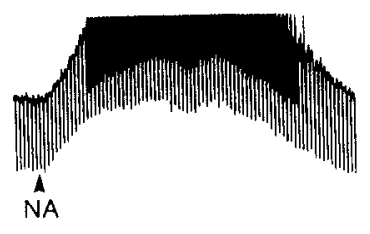

Post-Antagonist

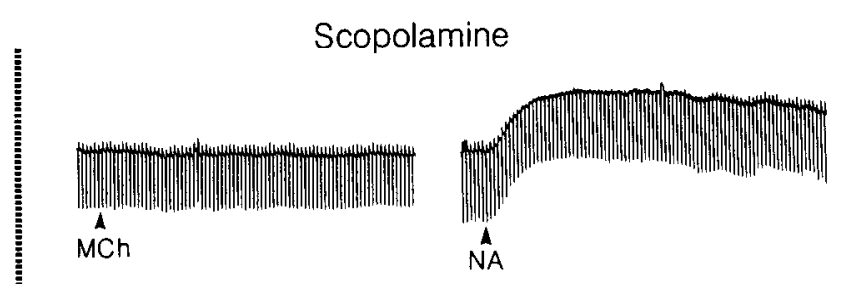

Prazosin

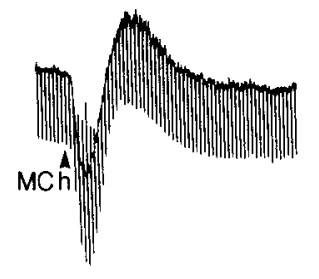

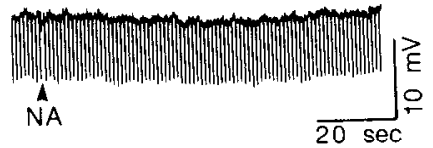

음

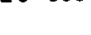

Figure 4. MCh and NA cause slow depolarizations through pharmacologically distinct receptors in guinea pig LGNd. A, Local application of scopolamine (10 $\mu \mathrm{M}$ in micropipette) completely blocks the response to MCh, but not to NA. $B$, Local application of the $\alpha_{1}$-adrenergic antagonist prazosin $(10 \mu \mathrm{M})$ completely blocks the slow depolarizing effect of NA, but not of MCh.

responses to $\mathrm{MCh}$ and NA was examined through the local or bath application of specific antagonists. Local application of the muscarinic antagonist scopolamine (10 $\mu \mathrm{M}$ in micropipette) completely blocked the response to $\mathrm{MCh}$, but did not alter the response to NA (Fig. $4 A ; n=3$ ). Similarly, local application of the $\alpha_{1}$-antagonist prazosin (10 $\mu \mathrm{M}$ in micropipetle) completely blocked the response to NA, but did not alter the response to ACh (Fig. 4B;n=3). These results indicate that NA and ACh depolarize LGNd relay neurons through pharmacologically distinct receptors, with little if any cross-activation by each agonist. The ability of prazosin to block the response to NA suggests that this response is mediated by $\alpha_{1}$-adrenoceptors. This result was confirmed by a lack of activation of this response by local application of the $\beta$-agonist isoprenaline (McCormick and Pape, 1990b).

\section{Characteristics of the current underlying the slow depolarization}

The voltage dependency of the current suppressed by $\mathrm{MCh}$ and NA was investigated by obtaining current versus voltage (I-V) relationships before and during the $\mathrm{MCh}$ - and NA-induced inward currents under voltage-clamp conditions. Inward currents induced by $\mathrm{MCh}$ and NA were consistently associated with a decrease in apparent input impedance at membrane potentials positive to approximately $-80 \mathrm{mV}$. However, the results were more variable at more negative membrane potentials, with some cells showing a clear reversal point (Fig. 5) and others exhibiting complicated and apparently voltage-dependent changes in input conductance (not shown). These variable characteristics of the transmitter responses may have resulted from an agonist-induced activation or inactivation of more than one ionic current or incomplete voltage control of the neuron. Indeed, we have recently found that hyperpolarization of thalamic neurons negative to approximately $-60 \mathrm{mV}$ results in the activation of a large inward cation current termed $I_{h}$ (McCormick and Pape, 1990 a). This hyperpolarization-activated current can be greatly enhanced by stimulation of $\beta$-adrenergic or serotoninergic re- ceptors (Pape and McCormick, 1989; McCormick and Pape, 1990b). To prevent confounding factors contributed by activation of $I_{h}$, we blocked this current by applying Picoliter size drops of bathing medium containing $\mathrm{Cs}^{+}(2-20 \mathrm{~mm})$ onto the surface of the slice over the recorded neuron just prior to and during examination of response to $\mathrm{NA}, \mathrm{ACh}$, or $\mathrm{MCh}$. Under these conditions, the NA- and $\mathrm{MCh}$-induced inward currents were always associated with a relatively linear change in $I-V$ relationship that reversed at -102.4 and $-101.4 \mathrm{mV}$, respectively (see Table 1; Fig. 6D,E). These reversal potentials are identical to that exhibited by the $\mathrm{MCh}$-induced outward current $(-101.6 \mathrm{mV})$ and the $\mathrm{GABA}_{\mathrm{B}}-$ receptor-mediated increase in outward current $(-107.3 \mathrm{mV})$, both of which we have previously shown to be due to an increase in $\mathrm{K}^{+}$conductance (McCormick and Prince, 1987; Crunelli et al., 1988).

Neurons in the cerebral cortex, hippocampus, and sympathetic ganglia respond to muscarinic receptor activation with a slow depolarization that results in part from a decrease in three distinct $\mathrm{K}^{+}$currents: $I_{\mathrm{M}}, I_{\mathrm{AHP}}$, and a resting "leak" potassium current (Brown and Adams, 1980; Madison et al., 1987; McCormick and Williamson, 1989). The M-current (muscarinesensitive) is a time- and voltage-dependent $\mathrm{K}^{+}$current that activates upon depolarization of the membrane potential positive to approximately $-70 \mathrm{mV}$ (Brown and Adams, 1980). The AHP current is a $\mathrm{Ca}^{2+}$-activated $\mathrm{K}^{+}$current and underlies the slow afterhyperpolarization ( $>1$ sec duration) following a train of action potentials (Pennefather et al., 1985).

The possible involvement of $I_{\mathrm{M}}$ or $I_{\mathrm{AHP}}$ in the muscarinic- or $\alpha_{1}$-adrenergic-induced slow depolarizing responses of LGNd relay neurons was examined through the use of current-clamp and single-electrode voltage-clamp techniques. The $\mathbf{M}$-current is typically examined by holding the cell in the activation range of $I_{M}$ (e.g., $-45 \mathrm{mV}$ ) and stepping to a more negative membrane potential (e.g., $-60 \mathrm{mV}$ ), which subsequently results in deactivation of this current over the next 100 msec or more. Stepping back to the more positive membrane potential again activates $I_{\mathrm{M}}$, which appears as a slowly activating outward current (Brown 

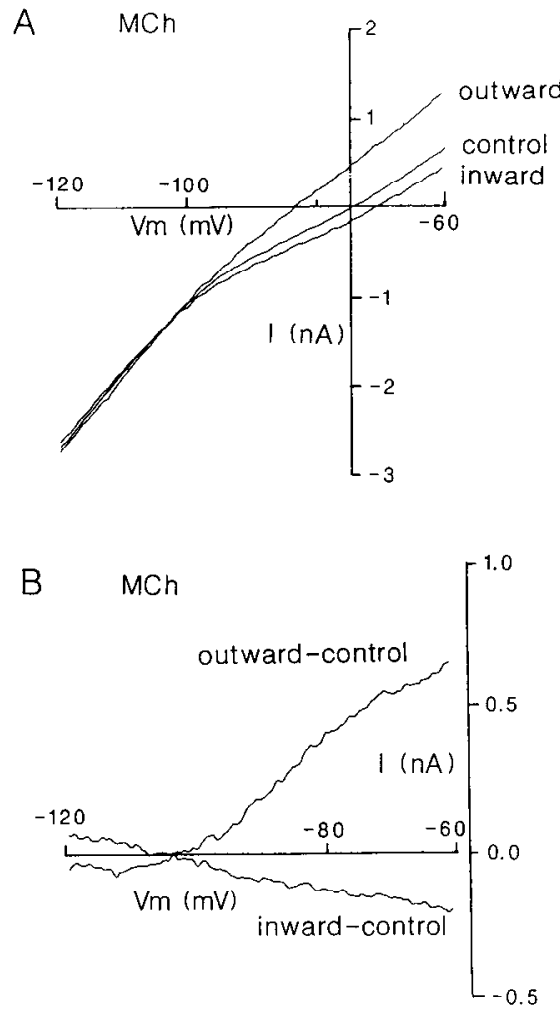

C

NA

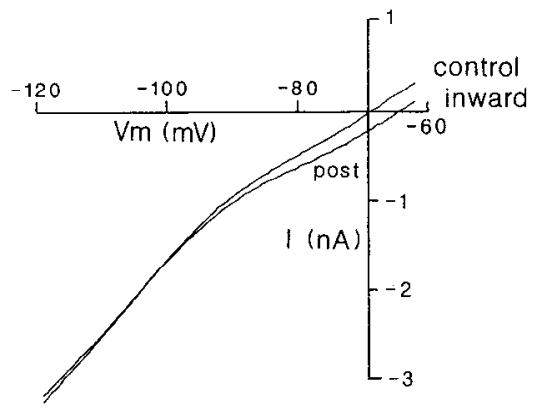

D NA

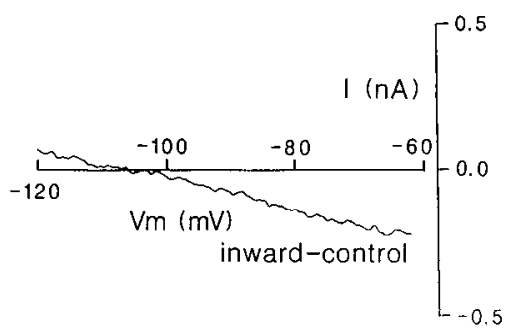

Figure 5. Voltage dependence of responses to MCh and NA. $A$, Current versus voltage plots obtained before (control), during the outward current (outward), and during the inward current (inward) responses activated in response to local application of $\mathrm{MCh} . B$, Subtraction of control $I-V$ plots from those obtained during the outward or inward currents reveal the voltage dependence of these two responses. $C, I-$ $V$ relations before (control) and during the NA-induced inward current (inward). $D$, Subtraction of control $I-V$ plots from the inward current plots reveal that the affected current varies in a relatively linear manner with membrane potential. All data obtained from the same guinea pig LGNd cell in normal bathing medium. and Adams, 1980). Voltage steps from -45 to $-60 \mathrm{mV}$ (after local application of $10 \mu \mathrm{M}$ tetrodotoxin) in thalamic relay neurons, which exhibited large slow depolarizing responses to $\mathrm{MCh}$ (Fig. 6A), were associated with fast current steps marked only by the presence of slowly inactivating transient outward currents elicited by the step from -60 to $-45 \mathrm{mV}$ ( $n=10$; Fig. $6 B, C$, Control; McCormick, 1991b). Slowly deactivating or activating outward currents indicative of $I_{M}$ were never observed (e.g., Fig. $6 C$ ). Application of $\mathrm{MCh}$ resulted in an inward current that was associated with a decrease in a portion of the "instantaneous" leak component of the current traces (Fig. $6 C$, MCh). Further investigation of the voltage-dependent properties of the $\mathrm{MCh}$ induced inward current through $I-V$ plots in the voltage range of -50 to $-130 \mathrm{mV}$ revealed in these cells that activation of muscarinic receptors results in an inward current that does not display the marked voltage dependence associated with $I_{\mathrm{M}}$ (Fig. $6 D, E$; Brown and Adams, 1980; McCormick and Williamson,
1989). These results suggest that reduction of $I_{M}$ does not contribute substantially to muscarinic- or $\alpha_{1}$-adrenergic-induced slow depolarizations studied here, although they do not rule out entirely the possible presence of $I_{\mathrm{M}}$ in thalamic relay neurons.

In the cerebral cortex and hippocampus, activation of $I_{\mathrm{AHP}}$ by a train of action potentials results in a slowing down of action potential discharge during the injection of a constant current pulse (i.e., spike frequency adaptation) and in the appearance of a prolonged (seconds) afterhyperpolarization following the cessation of the train of action potentials (Madison and Nicoll, 1984; Pennefather et al., 1985; McCormick and Williamson, 1989). In contrast to cortical pyramidal cells, suprathreshold depolarizations in thalamocortical relay cells result in a sustained discharge that lacks marked spike frequency adaptation or a slow afterhyperpolarization (Fig. $7 A, B$, Control), even after firing for many seconds (not shown). Application of $\mathrm{MCh}$ or NA to neurons during the periodic injection of depolarizing

\begin{tabular}{llllll}
\hline Table 1. Effect of pertussis toxin and GTP- $\boldsymbol{\gamma}$-S on agonist-evoked currents \\
$\begin{array}{l}\text { Reversal } \\
\text { potential } \\
(\mathrm{mV})\end{array}$ & $\begin{array}{l}\text { Control } \\
(\mathrm{pA})\end{array}$ & Pertussis toxin & Control & GTP- $\gamma-\mathrm{S}$ \\
Agonist & $-107.3 \pm 3.4$ & $-610 \pm 100$ & $-25 \pm 12.5^{*}$ & $-990 \pm 196$ & $0 \pm 0^{*}$ \\
Baclofen & $(n=4)$ & $(n=5)$ & $(n=5)$ & $(n=6)$ & $(n=7)$ \\
& $-101.6 \pm 2.7$ & $-345.6 \pm 39.2$ & $-18.8 \pm 20^{*}$ & $-535 \pm 69$ & $0 \pm 0^{*}$ \\
MCh (outward $I)$ & $(n=5)$ & $(n-9)$ & $(n=8)$ & $(n=7)$ & $(n=6)$ \\
MCh (inward $I)$ & $-101.4 \pm 3.3$ & $134.2 \pm 33.3$ & $141.2 \pm 23.3$ & $109 \pm 22$ & $105 \pm 27.7$ \\
& $(n=5)$ & $(n=6)$ & $(n=8)$ & $(n=7)$ & $(n=6)$ \\
NA & $-102.4 \pm 3.6$ & $208.8 \pm 41.4$ & $218 \pm 52$ & $320 \pm 53$ & $373 \pm 64$ \\
& $(n=5)$ & $(n=4)$ & $(n=5)$ & $(n=7)$ & $(n=10)$
\end{tabular}

Data are presented as mean \pm SEM. Currents are the peak response measured during voltage clamp to $-60 \mathrm{mV}$. ${ }^{*} p<0.001$. 


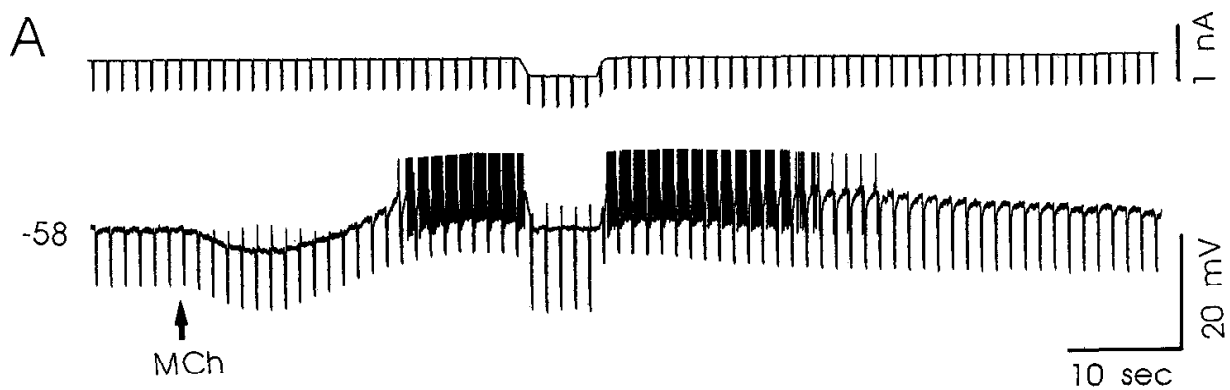

Figure 6. Lack of a prominent contribution of $I_{\mathrm{M}}$ to muscarinic-induced excitation in guinea pig LGNd neurons. $A$, Application of $\mathrm{MCh}$ to this neuron after depolarization with current injection to $-58 \mathrm{mV}$ results in a small hyperpolarization followed by a large slow depolarization. Compensation for the slow depolarization with the intracellular injection of current reveals that it is associated with a decrease in apparent input conductance. $B$, Effect of MCh on the currents associated with stepping from -45 to $-60 \mathrm{mV}$. Application of MCh results in an outward current followed by an inward current associated with a decrease in the apparent input conductance of the cell. Pulses were applied once every three seconds. $C$, Current traces prior (control) and after $(M C h)$ application of $\mathrm{MCh}$ are expanded for detail. $D$, Current versus voltage plots obtained prior to application of MCh (control), during the MCh-induced outward current (MCh outward), and during the $\mathrm{MCh}$-induced inward current (MCh inward). Both the outward and inward currents reverse al approximately $-95 \mathrm{mV}$, which is near $E_{\mathrm{K}}$. $E$, Subtraction of the control $I-V$ relation from those during the outward and inward MCh-induced currents reveal their voltage dependency. All data were obtained from the same guinea LGNd cell. Data in $B-E$ were obtained after block of voltage-activated $\mathrm{Na}^{+}$ currents with local application of tetrodotoxin $(10 \mu \mathrm{M})$. Data in $D$ and $E$ were obtaincd after block of $I_{b}$ with extracellular application of $\mathrm{CS}^{+}(20 \mathrm{~mm}$ in micropipette).
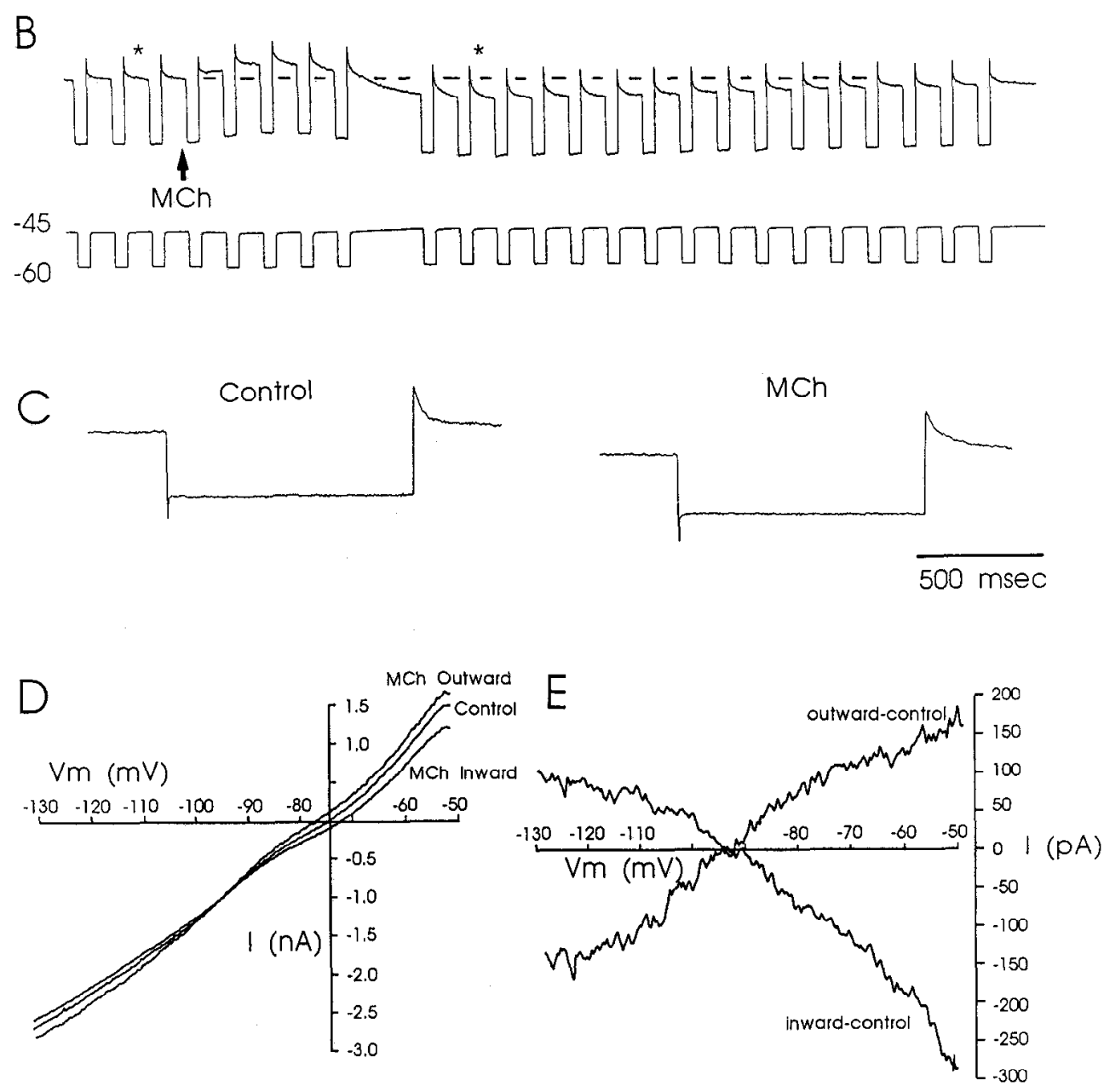

current pulses resulted in a slow depolarization of the membrane potential and an increase in the number of action potentials generated in response to the current pulse (Fig. $7 B$; compare Control, $\mathrm{MCh}$ ). However, this increase in responsiveness is due largely to the depolarization of the membrane potential, since compensation for the depolarization with the intracellular injection of current reinstated the original response of the neuron to the depolarizing current pulse (Fig. 7; compare Control, $\mathrm{MCh}$, - d.c.). Similarly, depolarization of the neuron through the intracellular injection of current after recovery from the $\mathrm{MCh}$ - or NA-induced slow depolarization resulted in a similar increase in responsiveness to the depolarizing current pulse (Fig. $7 B$, + d.c.).

These results indicate that stimulation of muscarinic or $\alpha_{1}-$ adrenergic receptors results in a slow depolarization through reduction of a $\mathrm{K}^{+}$current that is distinct from $I_{\mathrm{M}}$ and $I_{\mathrm{AHP}}$ and that is relatively linear in the voltage range of -120 to -60 $\mathrm{mV}$. The contribution of this $\mathrm{K}^{+}$current to the resting leak conductance of the cell prompted us to refer to it as $I_{\mathrm{KL}}$.

\section{Involvement of $G$-proteins}

The possible involvement of GTP-binding proteins (G-proteins) in the coupling of receptor to ionic responses has been suggested in the heart and a number of neuronal systems (see reviews by Brown, 1990; Szabo and Otero, 1990). The possible involvement of G-proteins in the responses reported here was examined either through the use of pertussis toxin, which ADP-ribosylates certain G-proteins such as $\mathrm{G}_{i}$ and $\mathrm{G}_{o}$ and therefore prevents them from interacting with their substrate (Bokoch et al., 1983), or through the intracellular injection of a nonhydrolyzable GTP 


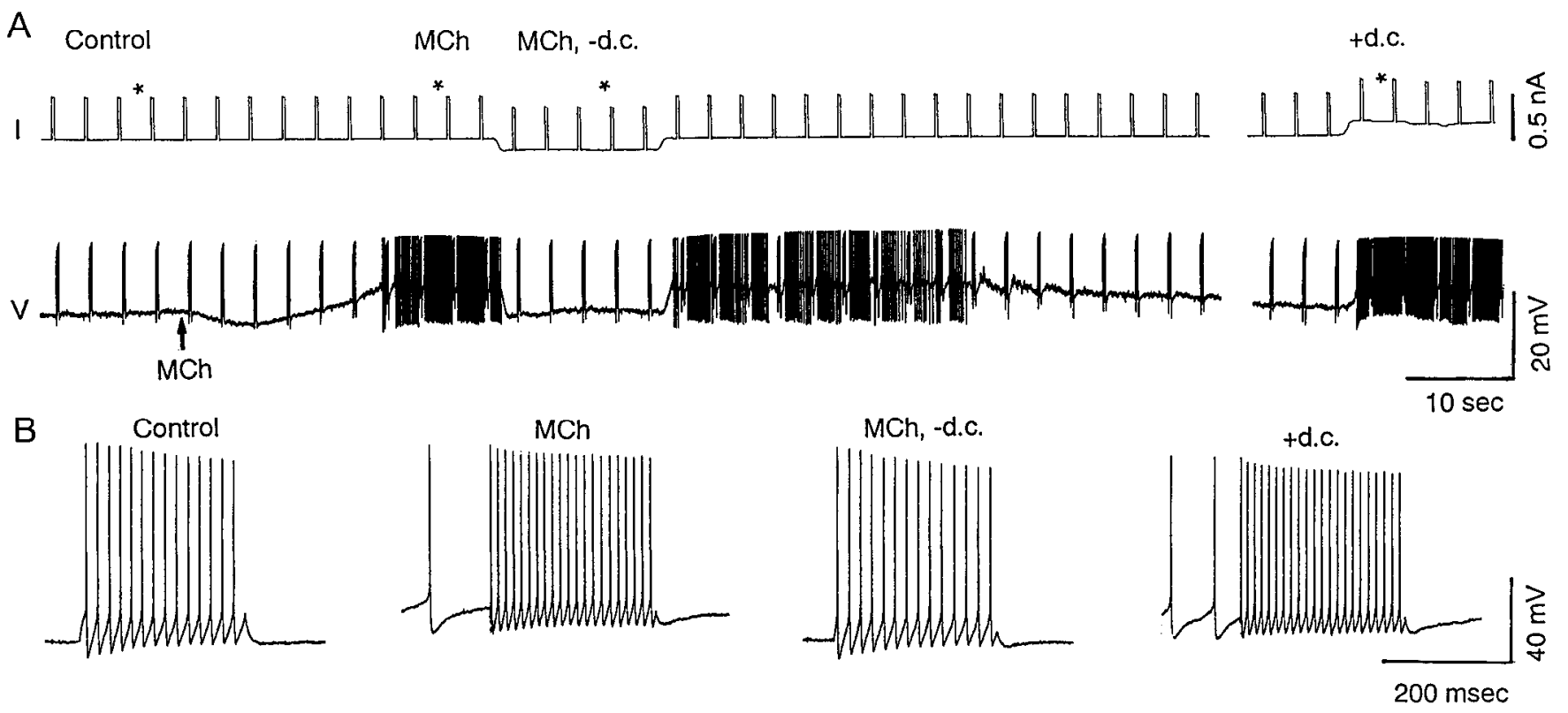

Figure 7. Lack of substantial spike frequency adaptation or a slow afterhyperpolarization in guinea pig thalamic relay neurons. $A$, Injection of a $0.5 \mathrm{nA}, 250 \mathrm{msec}$ depolarizing current pulse results in the activation of a train of 13-15 action potentials that is not associated with an appreciable slow afterhyperpolarization (cell at $-60 \mathrm{mV}$ ). Application of $\mathrm{MCh}$ results in a hyperpolarization followed by a slow depolarization and action potential generation. Asterisks indicate traces expanded in $B$ for detail. $B$, The response of the neuron to the depolarizing current pulse during the MCh-induced depolarization is enhanced $(M C h)$. Compensation for the depolarization with the injection of current reinstates the original response to the current pulse $(M C h,-d . c$.), indicating that the increase in responsiveness resulted largely from the depolarization. Similarly, depolarization of the neuron by an amount equal to that induced by $\mathrm{MCh}$ results in a similar increase in responsiveness $(A$ and $B,+d . c$.).

analog, GTP- $\gamma$-S. Pertussis toxin requires a substantial incubation period in vivo to be effective and therefore was injected unilaterally into the LGNd of guinea pigs 1-3 d prior to the experiment. Control neurons were obtained from the opposite LGNd that had received an injection of vehicle only.

Application of the $\mathrm{GABA}_{\mathrm{B}}$ agonist baclofen to neurons maintained in vitro and that had previously been exposed to pertussis toxin in vivo resulted in only a very small or no detectable current (Fig. 8, Pertussis Toxin), while application of baclofen to neurons exposed only to vehicle in the same animals resulted in the typical outward current response (Fig. 8, Control), as previously reported for hippocampal pyramidal cells (Andrade et al., 1986). The block of response to baclofen by pertussis toxin was statistically significant (Table 1). Similarly, application of MCh to neurons exposed to pertussis toxin yielded only very small or no outward current responses to this agonist in comparison to normal (Table 1, Fig. $8 B$ ).

In contrast, the $\mathrm{MCh}$-induced slow inward current appeared to be unaffected by pertussis toxin (Table 1, Fig. $8 B$ ). Similarly, neurons previously exposed to pertussis toxin yielded normal-

A

Pertussis Toxin

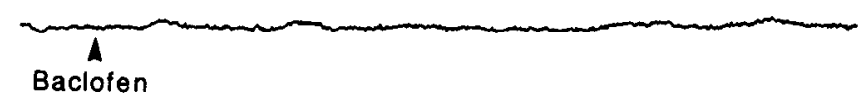

Control

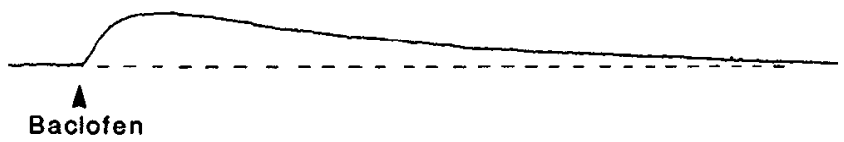

Pertussis Toxin

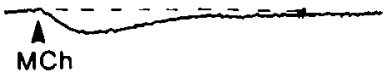

Control
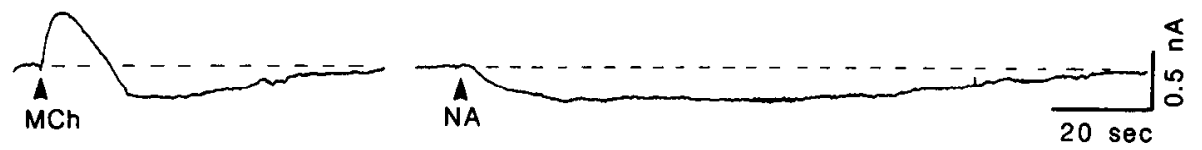

Figure 8. Effect of pertussis toxin on responses of guinea pig LGNd neurons to baclofen, MCh, and NA. Cells obtained in the LGNd on the side of prior in vivo injection of pertussis toxin $(1 \mu \mathrm{l}$ of $1 \mu \mathrm{g} / \mu \mathrm{l}$ ) fail to give any noticeable response to baclofen, respond to $\mathrm{MCh}$ with only the inward response $(B)$, and respond to NA with the normal inward current $(C)$. Cells obtained from the opposite LGNd, which was injected with the vehicle only, give normal-appearing responses to baclofen $(A), \mathrm{MCh}(B)$, and NA $(C)$ (Control). 
A

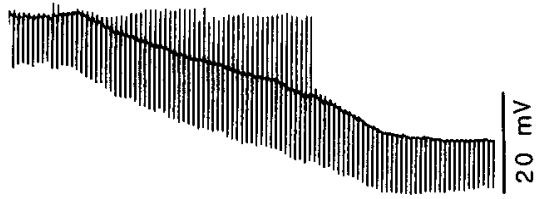

Figure 9. Effects of intracellular injection of the nonhydrolyzable GTP analog GTP- $\gamma-$ S. $A$, Soon after obtaining a stable intracellular recording from the guinea pig LGNd, neurons are found to undergo a large and steady hyperpolarization to a new resting membrane potential. These neurons fail to respond to baclofen ( $B$, upper trace) and give persistent inward currents to $\mathrm{MCh}(C$. upper trace) and NA (D, upper trace). Neighboring neurons recorded with normal electrodes exhibited normal responses to these three agonists $(B-D$, lower traces labeled control).

C GTP- $\gamma-\mathrm{s}$

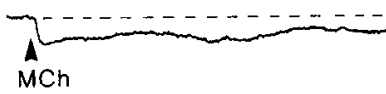

D

Control

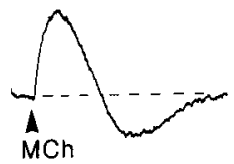

B

GTP- $\gamma-S$
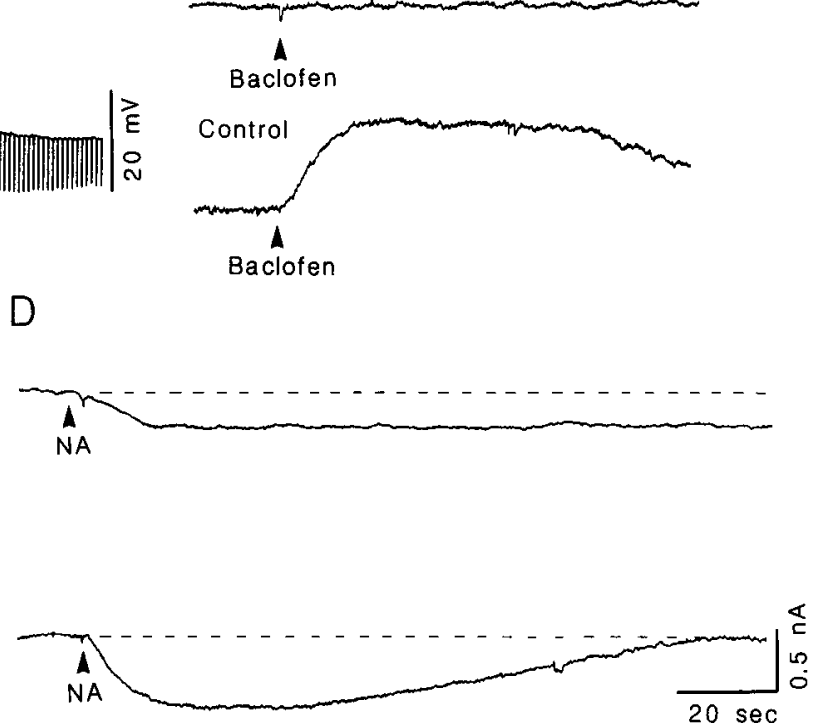

appearing responses to NA (Fig. $8 B$, Table 1), although the same cells failed to respond to either MCh or baclofen with significant outward currents (see above). Neurons previously exposed to pertussis toxin did not appear significantly different from normal cells in terms of their electrophysiological properties, including input resistance [pertussis: $35 \pm 3.5$ ( $\pm \mathrm{SEM}) \mathrm{M} \Omega$; normal: 32 $\pm 3.4 \mathrm{M} \Omega$ ] or resting membrane potential (pertussis: $-66 \pm$ $1.7 \mathrm{mV}$; normal: $-63 \pm 2 \mathrm{mV}$ ). These data suggest that the baclofen- and $\mathrm{MCh}$-induced increases in $\mathrm{K}^{+}$current occur through a pertussis toxin-sensitive $\mathrm{G}$-protein, while the $\mathrm{MCh}$ and NA-induced decreases in $\mathrm{K}^{+}$current may result through a non-pertussis toxin-sensitive G-protein. To examine these hypotheses further, we included GTP- $\gamma-\mathrm{S}$ in the recording microelectrode in high concentration ( $25 \mathrm{~mm}$ ), so as to allow diffusion of enough GTP- $\gamma-\mathrm{S}$ into the neuron to activate G-proteins irreversibly in the recorded neuron.

Impaling neurons with microelectrodes containing GTP- $\gamma-S$ resulted in a typical sequence of events. One to two minutes after impalement and initial settling of the membrane potential, neurons exhibited a steady and large hyperpolarization to a new resting membrane potential approximately $15-25 \mathrm{mV}$ negative to normal (Fig. 9A). This large hyperpolarization was associated with a substantial increase in apparent input conductance and was similar in amplitude to the hyperpolarization induced in normal cells by a maximal dosage of baclofen or MCh (not shown). Neurons recorded with GTP- $\gamma-S-$ containing microelectrodes and voltage clamped to approximately $-60 \mathrm{mV}$ failed to respond to baclofen (Fig. 9B, GTP- $\gamma-S$ ), while application of baclofen to neighboring neurons recorded with standard microelectrodes yielded normal responses (Fig. 9B, Control). This difference was statistically significant (Table $1 ; p<0.001$ ).

Application of $\mathrm{MCh}$ and NA to neurons recorded with GTP$\gamma-\mathrm{S}-$ containing microelectrodes resulted in slow inward currents that were unusual in that they were irreversible in nature (Fig. $9 C, D)$. A second, and sometimes third, application of $\mathrm{MCh}$ or NA could yield additional inward currents, although they were always of much smaller amplitude than the first and were also irreversible. Further applications did not yield any additional response, even after prolonged periods ( $1 \mathrm{hr}$ ). In contrast, neighboring neurons recorded with normal electrodes responded to repeated applications of $\mathrm{MCh}$ and NA with normal-appearing responses (Control, Fig. 9C,D; Table 1). The most parsimonious explanation of this result is that the $\mathrm{MCh}$ - and NA-induced block of a resting $\mathrm{K}^{+}$current involves the activation of a $\mathrm{G}$-protein that is not sensitive to pertussis toxin. This $\mathrm{G}$-protein may exhibit a slow rate of spontaneous GTP binding in the absence of agonist and therefore is only slowly activated by GTP- $\gamma-S$ prior to application of NA or MCh. Activation of muscarinic or $\alpha_{1}$-adrenergic receptors may then greatly increase the rate of GTP- $\gamma$-S binding to the G-protein, thereby resulting in an irreversible response (e.g., Breitwieser and Szabo, 1988). In contrast, the outward current activated by stimulation of $\mathrm{GABA}_{\mathrm{B}}$ and muscarinic receptors appears to be mediated by an outward current that has a high rate of spontaneous GTP binding in the apparent absence of agonist, since this response became maximal prior to application of MCh or baclofen.

\section{Discussion}

Our present results reveal that activation of muscarinic and $\alpha_{1}$ adrenergic receptors on cat or guinea pig LGNd relay neurons can result in substantial depolarization through reduction of a $\mathrm{K}^{+}$conductance that is active at resting membrane potentials. In the guinea pig LGNd, the amplitude of this current varied in a relatively linear manner in relation to the driving force upon $\mathrm{K}^{+}$ions $\left(V-E_{\mathrm{K}}\right)$ in the membrane potential range of -50 to $-120 \mathrm{mV}$, suggesting that it is distinct from the highly voltage-dependent $\mathrm{K}^{+}$current known as $I_{\mathrm{M}}$ (Brown and Adams, 1980; Brown et al., 1989; McCormick and Williamson, 1989). Indeed, we have recently demonstrated that this current persists in thalamic reticular neurons after bath applications of $\mathrm{Ba}^{2+}$, which blocks $I_{\mathrm{M}}$ (Constanti et al., 1981), confirming the separate identities of these two currents (McCormick and Wang, 1991). Thalamocortical relay neurons in the guinea pig and cat LGNd also appear to express little of the slow $\mathrm{Ca}^{2+}$-activated $\mathrm{K}^{+}$current known as $I_{\mathrm{AHP}}$ (Pennefather et al., 1985) since prolonged trains of action potentials (Fig. 7) or even the generation of repeated 
high-threshold or low-threshold $\mathrm{Ca}^{2+}$ spikes (not shown) were not followed by the generation of a slow afterhyperpolarization. In addition, the slow depolarizing response resulting from activation of muscarinic or $\alpha_{1}$-adrenergic receptors is unlikely to result from a reduction in a $\mathrm{Ca}^{2+}$-activated $\mathrm{K}^{+}$current since these responses persist after the block of transmembrane $\mathrm{Ca}^{2+}$ currents (McCormick and Prince, 1987, 1988). Therefore, we were unable to confirm the suggestion by Sherman and Koch (1986) that modulation of $I_{\mathrm{AHP}}$ and/or $I_{\mathrm{M}}$ may underlie the excitatory effects of ACh and NA in the LGNd. Although we have not yet specifically addressed the possible presence and modulation of $I_{\mathrm{M}}$ in cat LGNd neurons, the presence of the slow depolarizing response even at negative membrane potentials in this species (e.g., Fig. 2) suggests that cholinergic and noradrenergic reduction of $I_{\mathrm{KL}}$ is also prevalent in these neurons. The nonadditive nature of the cholinergic and noradrenergic slow depolarizations or inward currents in guinea pig LGNd suggests that these two transmitters are capable of reducing the same $\mathrm{K}^{+}$ current. This hypothesis is supported by the similar voltage dependency of the current reduced by these two agents (see Fig. 5). However, it is also possible that the postsynaptic actions of these two transmitters interact prior to convergence onto the same $\mathrm{K}^{+}$channels, such as through competition for the same class of G-protein or second-messenger system.

In addition to the slow depolarization, activation of muscarinic receptors on guinea pig LGNd relay neurons is capable of activating an increase in $\mathrm{K}^{+}$conductance. This potassium conductance is also activated by stimulation of $\mathrm{GABA}_{\mathrm{B}}$ and purinergic receptors (McCormick, 1988) and appears to be distinct from that reduced by NA, since maximal application of NA failed to reduce, and in fact often enhanced, the hyperpolarizing response to ACh or MCh (see Fig. 4). However, confirmation of the proposed distinct nature of these two currents must await singlechannel analysis.

\section{Involvement of $G$-proteins in responses to $M C h$ and $N A$}

Our present data suggest that the muscarinic- and $\mathrm{GABA}_{\mathrm{B}}$-mediated increases in $\mathrm{K}^{+}$conductance in guinea pig LGNd relay cells are mediated by a pertussis toxin-sensitive G-protein, while the muscarinic and $\alpha_{1}$-adrenergic receptor-mediated decreases in $\mathrm{K}^{+}$conductance are also mediated by a G-protein, but one that is not readily ADP-ribosylated by pertussis toxin. The possible involvement of pertussis toxin-sensitive G-proteins in agonist-induced increases in $\mathrm{K}^{+}$conductances in neurons has been suggested previously (see Andrade et al., 1986; North, 1986; Nicoll, 1988; Brown, 1990). In agreement with these physiological studies, we have found that intracellular application of high concentrations of the nonhydrolyzable GTP analog GTP$\gamma-\mathrm{S}$ results in a tonic increase in $\mathrm{K}^{+}$conductance that occludes further increases in $\mathrm{K}^{+}$conductance when muscarinic or $\mathrm{GABA}_{\mathrm{B}}$ receptors are activated (Fig. 9), presumably through a ceiling effect. In addition, prior exposure to pertussis toxin effectively uncoupled muscarinic and $\mathrm{GABA}_{\mathrm{B}}$ receptors from this increase in $\mathrm{K}^{+}$conductance (Fig. 8). In the heart, ACh-induced increases in $\mathrm{K}^{+}$conductance have been proposed to involve the liberation of activated $\alpha$-subunits from a pertussis toxin-sensitive G-protein. Binding of ACh to muscarinic receptors splits the G-protein into two components: an $\alpha$-subunit bound to GTP ( $\alpha$-GTP) and the $\beta$ - and $\gamma$-subunits bound together (see Birnbaumer et al., 1990). It is the $\alpha$-GTP complex that is believed subsequently to activate the appropriate nearby $\mathrm{K}^{+}$channels (Birnbaumer et al., 1990). The similarity of the increase in $\mathrm{K}^{+}$conductance in response to activation of muscarinic receptors in thalamic neurons to that of the heart suggests that similar subcellular mechanisms may be responsible, although this remains to be confirmed through detailed patch-clamp analysis. For example, application of $\mathrm{G}_{o}$ to membrane patches of hippocampal pyramidal cells activates at least four different types of $\mathrm{K}^{+}$channel, indicating a level of complexity that has not yet been demonstrated in heart cells (VanDongen et al., 1988).

Our present results suggest that GTP-binding proteins are also involved in the slow depolarizations induced by activation of muscarinic and $\alpha_{1}$-adrenergic receptors in LGNd relay neurons (Figs. 8, 9), although these G-proteins appear not to be pertussis toxin sensitive. The involvement of G-proteins in the reduction of resting leak conductances by $\mathrm{ACh}$ has not previously been investigated in detail, although one preliminary investigation reported that a non-pertussis toxin-sensitive G-protein was involved in the suppression of a resting $\mathrm{K}^{+}$conductance by $\mathrm{ACh}$ in hippocampal pyramidal cells (Brown et al., 1988). In sympathetic ganglion cells, reduction of M-current by ACh appears to involve the activation of a non-pertussis toxin-sensitive G-protein (Pfaffinger, 1988; Brown et al., 1989; Brown, 1990). Similarly, although activation of $\alpha_{1}$-adrenoceptors results in excitation through inhibition of $\mathrm{K}^{+}$currents in a number of brain regions (see McCormick, 1991a, for review), the possible involvement of G-proteins in this response has not been thoroughly addressed. In the heart, activation of $\alpha_{1}$-adrenoceptors results in reduction of a leak $\mathrm{K}^{+}$conductance and may involve a pertussis toxin-sensitive G-protein (Shah et al., 1988). However, pharmacological investigations have demonstrated that although all $\alpha_{1}$-adrenoceptors appear to be coupled to G-proteins, some are sensitive to inhibition by pertussis toxin while others are not (see Minneman et al., 1991). This variation in G-protein coupling of $\alpha_{1}$-adrenoceptors may correlate with the various subtypes of this class of receptor (Minneman et al., 1991).

\section{Functional consequences of muscarinic-and $\alpha_{1}$-adrenergic-induced depolarizations}

Thalamic relay neurons display two basic patterns of activity both in vivo and in vitro: rhythmic burst firing and single spike activity (Jahnsen and Llinás, 1984a,b; Steriade and Deschênes, 1984; McCormick and Pape, 1990a). Rhythmic burst firing, in vitro, or in vivo during periods of deep sleep or anesthesia, appears as a slow oscillation in the frequency range of delta waves $(0.5-4 \mathrm{~Hz})$ and results from the generation of low-threshold $\mathrm{Ca}^{2+}$ spikes, the timing of which is determined by the hyperpolarization-activated cation current $I_{h}$ (McCormick and Pape, 1990a; Curró Dossi et al., 1991b; Steriade et al., 1992). In addition, spindle oscillations, which are $7-12 \mathrm{~Hz}$ circuit oscillations between the $\mathrm{nRt}$ and thalamic relay cells, also appear in vivo during slow-wave sleep and anesthesia (Steriade and Deschênes, 1984). Depolarization of LGNd relay neurons, such as that which occurs naturally during wakening from slow-wave sleep (Hirsch et al., 1983), abolishes rhythmic burst firing through inactivation of the low-threshold $\mathrm{Ca}^{2+}$ current and replaces this activity with tonic, single spike firing (see Fig. 2D). Functionally, this switch to single spike activity is associated with a large increase in responsiveness to, and ability to follow faithfully, excitatory potentials, thereby increasing the transmittal of sensory inputs (Coenen and Vendrik, 1972; Livingstone and Hubel, 1981; Steriade and Llinás, 1988; McCormick and Feeser, 1990). Our present data reveal that activation of either muscarinic or $\alpha_{1}$ - 
adrenergic receptors can result in a complete shift in firing mode of cat LGNd relay neurons from slow rhythmic burst firing to tonic, single spike activity (see Fig. 1), thereby suggesting that release of $\mathrm{NA}$ and/or $\mathrm{ACh}$ may be responsible, in vivo, for the similar shift in firing mode that is associated with increases in arousal and attentiveness (Hirsch et al., 1983). Indeed, electrical stimulation in the region of either the brainstem cholinergic or noradrenergic neurons that innervate the LGNd results in slow depolarization, suppression of rhythmic burst firing, and the promotion of single spike activity through the activation of muscarinic and $\alpha_{1}$-adrenergic receptors (Rogawski and Aghajanian, 1980; Kayama et al., 1982; Hu et al., 1989; Deschênes and Hu, 1990; Curró Dossi et al., 1991a). Although it has been suggested that the depolarization mediated by the activation of muscarinic receptors may be mediated by suppression of the M-current (Sherman and Koch, 1986; Curró Dossi et al., 1991a), our present results indicate that the most prominent effect is likely to be the suppression of $I_{\mathrm{KL}}$. The relatively linear nature of $I_{\mathrm{KL}}$ has the functional consequence that this current is active at all membrane potentials and therefore activation of muscarinic or $\alpha_{1}$-receptors will result in suppression of slow rhythmic burst firing, which occurs at membrane potentials between -70 and $-85 \mathrm{mV}$ (McCormick and Pape, 1990a), and the promotion of single spike activity. The amplitude of the resulting depolarization will, of course, depend upon the membrane potential prior to activation of these receptors (McCormick and Prince, 1987), since more hyperpolarized membrane potentials are associated with a decrease drive on $\mathrm{K}^{+}$.

In addition to the block of $I_{\mathrm{KL}}$ shown here in response to activation of muscarinic and $\alpha_{1}$-adrenergic receptors, we have also recently described the block of this current in response to activation of $\mathrm{H}_{1}$ histaminergic receptors in LGNd relay cells (McCormick and Williamson, 1991) and 5- $\mathrm{HT}_{2}$ serotoninergic receptors in $\mathrm{nRt}$ neurons (McCormick and Wang, 1991). In agreement with the present results, these responses were found to occlude with maximal activation of $\alpha_{1}$-adrenergic receptors, implying postsynaptic convergence of action. Based upon these and other results (see reviews by McCormick, 1989; Steriade and McCarley, 1990), we would like to propose that the increased activity of brainstem cholinergic, noradrenergic, serotoninergic, and hypothalamic histaminergic pathways that occurs during increases in arousal and attentiveness (Trulson and Jacobs, 1979; Aston-Jones and Bloom, 1981; Vanni-Mercier et al., 1984; Steriade et al., 1990) results in an abolition of rhythmic burst firing in thalamic neurons and thalamocortical systems and the promotion of single spike activity. These changes in thalamocortical activity, in turn, result in suppression of synchronized slow waves in the electroencephalogram and promote a state of activity that is conducive to cognition. Further detailed investigations are required to reveal the unique function that each of these neurotransmitter systems contribute to this process of ascending modulation of thalamocortical activity.

\section{References}

Andrade R, Malenka RC, Nicoll RA (1986) A G-protein couples serotonin and $\mathrm{GABA}_{\mathrm{B}}$ receptors to the same channels in hippocampus. Science 234:1261-1265.

Aston-Jones G, Bloom FE (1981) Activity of norepinephrine-containing locus coeruleus neurons in behaving rats anticipates fluctuations in the sleep-waking cycle. J Neurosci 1:876-886.

Birnbaumer L, Yatani A, VanDongen AMJ, Graf R, Codina J, Okabe K, Mattera R, Brown AM (1990) G-protein coupling of receptors to ionic channels and other effector systems. Br J Clin Pharmacol 30: 13S-22S.

Bokoch GM, Katada T, Northup JK, Hewlett EL, Gilman AG (1983) Identification of the predominant substrate for ADP-ribosylation by islet activating protein. J Biol Chem 258:2072-2075.

Breitwieser GE, Szabo G (1988) Mechanisms of muscarinic receptorinduced $\mathrm{K}^{+}$channel activation as revealed by hydrolysis-resistant GTP analogues. J Gen Physiol 91:469-493.

Brown DA (1990) G-proteins and potassium currents in neurons. Annu Rev Physiol 52:215-242.

Brown DA, Adams PR (1980) Muscarinic suppression of a noval voltage-sensitive $\mathrm{K}^{+}$current in a vertebrate ncuronc. Nature 283:673676.

Brown DA, Marrion NV, Smart TG (1989) On the transduction mechanism for muscarine-induced inhibition of $\mathrm{M}$-current in cultured rat sympathetic neurones. J Physiol (Lond) 413:469-488.

Brown LD, Nakajima S, Nakajima Y (1988) Acetylcholine modulates a resting K-current through a pertussis toxin-resistant G-protein in hippocampal neurons. Soc Neurosci Abstr 14:1328.

Coenen AML, Vendrik AJH (1972) Determination of the transfer ratio of cat's geniculate neurons through quasi-intracellular recordings and the relation with the level of alertness. Exp Brain Res 14:227-242.

Constanti A, Adams PR, Brown DA (1981) Who do barium ions imitate acetylcholine? Brain Res 206:244-250.

Crunelli V, Haby M, Jassik-Gershenfeld D, Leresche N, Pirchio M (1988) $\mathrm{Cl}^{-}$and $\mathrm{K}^{+}$-dependent inhibitory postsynaptic potentials evoked by interneurones of the rat lateral geniculate nucleus. J Physiol (Lond) 399:153-176.

Curró Dossi R, Paré D, Steriade M (1991a) Short-lasting nicotinic and long-lasting muscarinic depolarizing responses of thalamocortical neurons to stimulation of mesopontine cholinergic nuclei. J Neurophysiol 65:393-408.

Curró Dossi R, Nunez A, Steriade M (1991b) Electrophysiology of a slow intrinsic oscillation in thalamocortical cells of cat in vivo. J Physiol (Lond), in press.

Deschênes M, Hu B (1990) Membrane resistance increase induced in thalamic neurons by stimulation of brainstem cholinergic afferents. Brain Res 513:339-342.

Hirsch JC, Fourment A, Marc ME (1983) Sleep-related variations of mombrane potential in the lateral geniculate body relay neurons of the cat. Brain Res 259:308-312.

Hu B, Steriade M, Deschênes M (1989) The effects of brainstem peribrachial stimulation on perigeniculate neurons: the blockage of spindle waves. Neuroscience 31:1-12.

Jahnsen H, Llinás R (1984a) Electrophysiological properties of guineapig thalamic neurons: an in vitro study. J Physiol (Lond) 349:205226.

Jahnsen H, Llinás R (1984b) Ionic basis for the electroresponsiveness and oscillatory properties of guinea-pig thalamic neurons in vitro. J Physiol (Lond) 349:227-247.

Kayama Y, Negi T, Sugitani M, Iwama K (1982) Effects of locus coeruleus stimulation on neuronal activities of dorsal lateral geniculate nucleus and perigeniculate reticular nucleus of the rat. Neuroscience 7:655-666.

Lamarre Y, Filion M, Cordeau JP (1971) Neuronal discharge of the ventrolateral nucleus of the thalamus during sleep and wakefulness in the cat. I. Spontaneous activity. Exp Brain Res 12:480-498.

Livingstone MS, Hubel DH (1981) Effects of sleep and arousal on the processing of visual information in the cat. Nature 291:554-561.

Madison DV, Nicoll RA (1984) Control of repetitive discharge of rat CA1 pyramidal neurons in vitro. J Physiol (Lond) 354:319-331.

Madison DV, Lancaster B, Nicoll RA (1987) Voltage clamp analysis of cholinergic action in the hippocampus. J Neurosci 7:733-741.

McCarley RW, Benoit O, Barrionuevo G (1983) Lateral geniculate unitary discharge in sleep and waking: state- and rate-specific aspects. J Neurophysiol 50:798-818.

McCormick DA (1988) Interactions and possible second messenger systems involved in neurotransmitter responses in the thalamus. Soc Neurosci Abstr 14:913.

McCormick DA (1989) Cholinergic and noradrenergic modulation of thalamocortical processing. Trends Neurosci 12:215-221.

McCormick DA (1991a) Electrophysiological consequences of activation of adrenoceptors in the CNS. In: Adrenoceptors: structure, mechanisms, function. Advances in pharmacological sciences (Szabadi E, Bradshaw CM, eds), pp 159-169. Basel: Birhauser. 
McCormick DA (1991b) Functional properties of a slowly inactivating potassium current, $\mathbf{I}_{\mathrm{As}}$, in guinea pig dorsal lateral geniculate relay neurons. J Neurophysiol 66:1176-1189.

McCormick DA, Feeser HR (1990) Functional implications of burst firing and single spike activity in thalamic neurons. Neuroscience 39: 103-113.

McCormick DA, Pape H-C (1988) Acetylcholine inhibits identified interneurons in the cat lateral geniculate nucleus. Nature 334:246248.

McCormick DA, Pape H-C (1990a) Properties of a hyperpolarizationactivated cation current and its role in rhythmic oscillation in thalamic relay neurons. J Physiol (Lond) 431:291-318.

McCormick DA, Pape H-C (1990b) Noradrenergic and serotonergic modulation of a hyperpolarization-activated cation current in thalamic relay neurons. J Physiol (Lond) 431:319-342.

McCormick DA, Prince DA (1987) Actions of acetylcholine in the guinea-pig and cat medial and lateral geniculate nuclei, in vitro. J Physiol (Lond) 392:147-165.

McCormick DA, Prince DA (1988) Noradrenergic modulation of firing pattern in guinea pig and cat thalamic neurons, in vitro. $J$ Neurophysiol 59:978-996.

McCormick DA, Wang Z (1991) Serotonin and noradrenaline excite GABAergic neurones of the guinea pig and cat thalamic reticular nucleus. J Physiol (Lond) 442:235-255.

McCormick DA, Williamson A (1989) Convergence and divergence of neurotransmitter action in human cerebral cortex. Proc Natl Acad Sci USA 86:8098-8102.

McCurmick DA, Williamson A (1991) Modulation of neuronal firing mode in cat and guinea pig LGNd by histamine: possible cellular mechanisms of histaminergic control of arousal. J Neurosci 11:31883199.

Minneman KP, Wilson KM, Han C (1991) $\alpha_{1}$-Adrenergic receptor subtypes: pharmacology and signal transduction. In: Adrenoceptors: structure, mechanisms, function. Advances in pharmacological sciences (Szabadi E, Bradshaw CM, eds), pp 15-25. Basel: Birkhauser.

Nicoll RA (1988) The coupling of neurotransmitter receptors to ion channels in the brain. Science 241:535-541.

North RA (1986) Receptors on individual neurons. Neuroscience 17: 899-907.

Pape H-C, McCormick DA (1989) Noradrenaline and serotonin selectively modulate thalamic burst firing by enhancing a hyperpolarization-activated cation current. Nature 340:715-718.

Pennefather P, Lancaster B, Adams PR, Nicoll RA (1985) Two distinct
Ca-dependent $\mathrm{K}$ currents in bullfrog sympathetic ganglion cells. Proc Natl Acad Sci USA 82:3040-3044.

Pfaffinger $P$ (1988) Muscarine and t-LHRH suppress M-current by activating an IAP-insensitive G-protein. J Neurosci 8:3343-3353.

Rogawski MA, Aghajanian GK (1980) Modulation of lateral geniculate neurone excitability by noradrenaline microiontophoresis or locus coeruleus stimulation. Nature 287:731-734.

Shah A, Cohen IS, Rosen MR (1988) Stimulation of cardiac alpha receptors increases $\mathrm{Na} / \mathrm{K}$ pump current and decreases $\mathrm{gK}$ via a pertussis toxin-sensitive pathway. Biophys J 54:219-225.

Sherman SM, Koch C (1986) The control of retinogeniculate transmission in the mammalian lateral geniculate nucleus. Exp Brain Res 63:1-20.

Steriade M, Deschênes M (1984) The thalamus as a neuronal oscillator. Brain Res Rev 8:1-63.

Steriade M, Llinás RR (1988) The functional states of the thalamus and the associated neuronal interplay. Physiol Rev 68:649-742.

Steriade M, McCarley RW (1990) Brainstem control of wakefulness and sleep. New York: Plenum.

Steriade M, Deschênes M, Domich L, Mulle C (1985) Abolition of spindle oscillations in thalamic neurons disconnected from nucleus reticularis thalami. J Neurophysiol 54:1473-1497.

Steriade M, Datta S, Paré D, Oakson G, Curró Dossi R (1990) Neuronal activities in brain-stem cholinergic nuclei related to tonic activation processes in thalamocortical systems. J Neurosci 10:25412559.

Steriade M, Curró Dossi R, Nuñez A (1992) Network modulation of a slow intrinsic oscillation of cat thalamocortical neurons implicated in sleep delta waves: cortical potentiation and brainstem cholinergic suppression. J Neurosci, in press.

Szabo G, Otero AS (1990) G protein mediated regulation of $\mathrm{K}^{+}$channels in heart. Annu Rev Physiol 52:293-305.

Trulson ME, Jacobs BL (1979) Raphe unit activity in freely moving cats: correlation with level of behavioral arousal. Brain Res 163:135150 .

VanDongen AMJ, Codina J, Olate J, Mattera R, Joho R, Birnbaumer L, Brown AM (1988) Newly identified brain potassium channels gated by the guanine nucleotide binding protein $\mathrm{G}_{o}$. Science 242 : 1433-1437.

Vanni-Mercier G, Sakai K, Jouvet M (1984) "Waking state specific" neurons in the caudal hypothalamus of the cat. C R Acad Sci [D] (Paris) 298:195-220. 